\title{
Changes in Steroidogenic ultrastructural features of corpus luteum in the turtle Chelydra serpentina relative to hormonal levels under natural conditions
}

\author{
T. Ba-Omar, A. Y. Al-Kindi \& I. Y. Mahmoud
}

Department of Biology, College of Science, Sultan Qaboos University, PO Box 36 Al-Khod, Postal Code 123, Muscat, Sultanate of Oman.

The activity of corpora lutea in snapping turtle, Chelydra serpentina was studied throughout its life span relative to changes in ultrastructural steroidogenic features and circulating plasma progesterone. Ultrastructural features such as tubular smooth endoplasmic reticulum (SER) and mitochondria with tubular cristae were examined during active phase of the corpus luteum (3weeks). During this time, they undergo hypertrophy (luteinization) to become granulosa lutein cells, similar to those in other vertebrates. There is a positive correlation between progesterone $(\mathrm{P})$ levels and the steroidogenic ultrastructural activity of the granulosa lutein cells. The Pro levels were $(0.99 \pm 0.06) \mathrm{ng} / \mathrm{ml}$ when the granulosa cells were steroidogenically active, however, when luteolysis was underway, progesterone levels began to drop $(0.8 \pm 0.04) \mathrm{ng} / \mathrm{ml}$. There were significant differences among Pro levels throughout the cycle. The corpus luteum is capable of converting pregnonolone to progesterone and cholesterol to progesterone $[1,2]$. The regression of the granulosa cells is not abrupt. There is a general disruption of the SER and mitochondria and the tubular ER becomes extremely vesiculated.

The snapping turtle oviposits a single clutch annually and ovulates within a short period (24- $48 \mathrm{hr}$ ). Thus all the corpora lutea are approximately at the same stage of activity. The corpora lutea remain active synthesizing steroids (steroidogenesis) for about 3 weeks after ovulation, mainly when the eggs are still retained in the uterus. Afterward, the corpora lutea begin to regress in size and after 2 weeks they completely disappear from the ovarian stroma.

After ovulation the thecal wall of the preovulatory follicle collapses and becomes thicker and thrown into folds, and eventually the folds disappear and the follicular wall becomes a disc-shaped corpus luteum (CL). Under the influence of luteinization, the granulosa follicular cells of the preovulatory follicle are transformed to granulosa lutein cells, which become the steroidogenic cells of the corpus luteum. The active lutein cell ER is frequently organized into concentric whorls or elaborate folded membrane arrays. The folded membrane arrays and the whorls are often associated with lipid droplets or mitochondria. Cholesterol synthesis takes place in the lipid droplets[1,2] and cholesterol undergoes side chain cleavage before entering the steroidogenic pathway.

Pregnenolone synthetase, the enzyme responsible for this cleavage, probably resides in the mitochondrion [3]. The close association between lipid droplets and mitochondria suggests a cholesterol-mitochondrion interaction. Lipid droplets may supply the mitochondria with sterol precursor as well as a source of energy.

References

[1] J. Klicka and I.Y. Mahmoud, Gen. Comp. Endocrinol. 19:367-369, 1972.

[2] J. Klicka and I.Y. Mahmoud, Steroids. 21:483-495, 1973.

[3] R.I. Dorfman and F. Ungar, Metabolism of Steroid Hormones. Academic Press Inc, NY. 1965. 


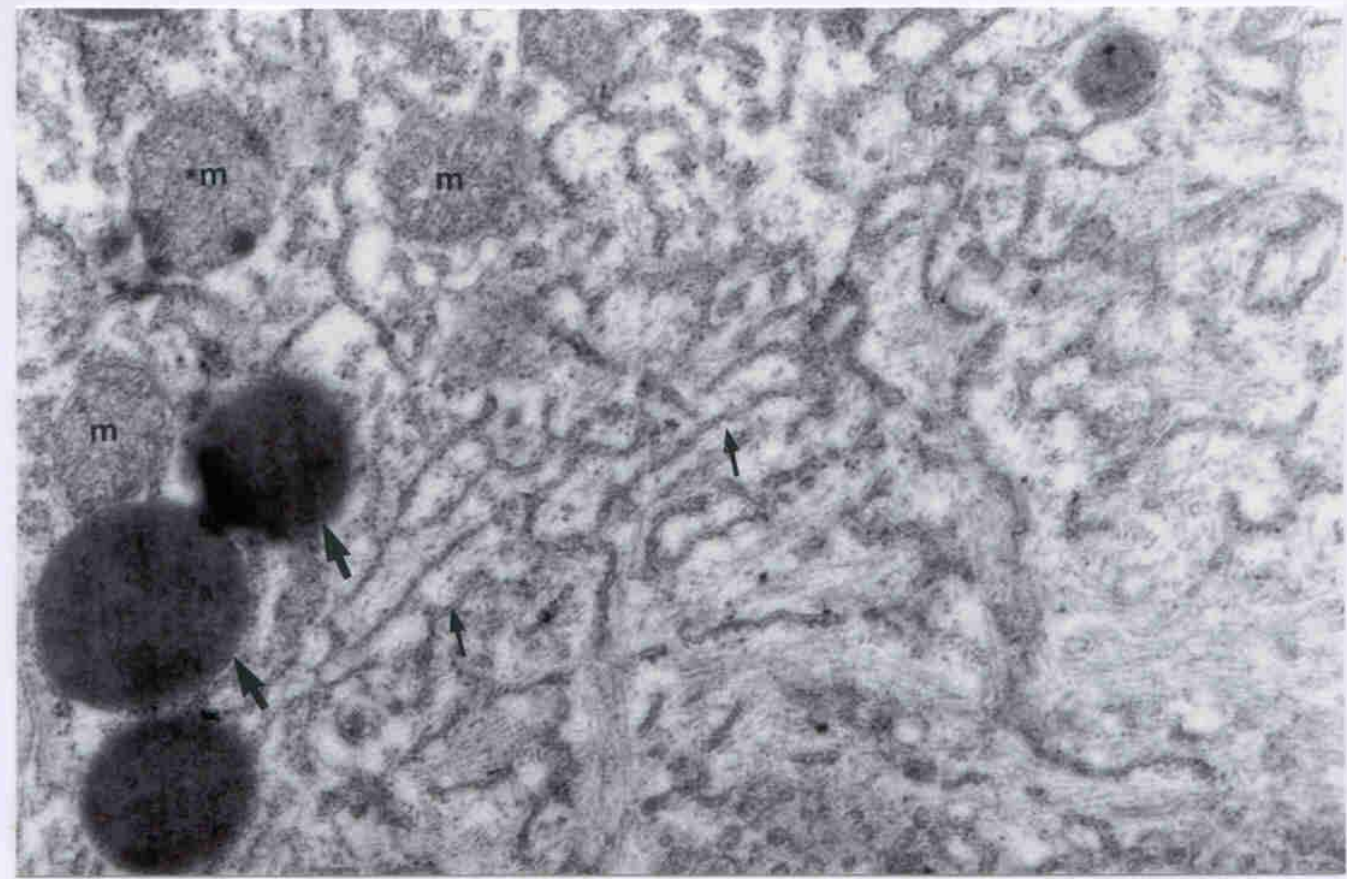

Fig.1. Active lutein cell during peak of steroidogenesis. Notice the abundance of smooth ER (small arrows) and the association of mitochondria (m) with ER, and also the association of lipid droplets (large arrows) with ER and mitochondria. (X 20000).

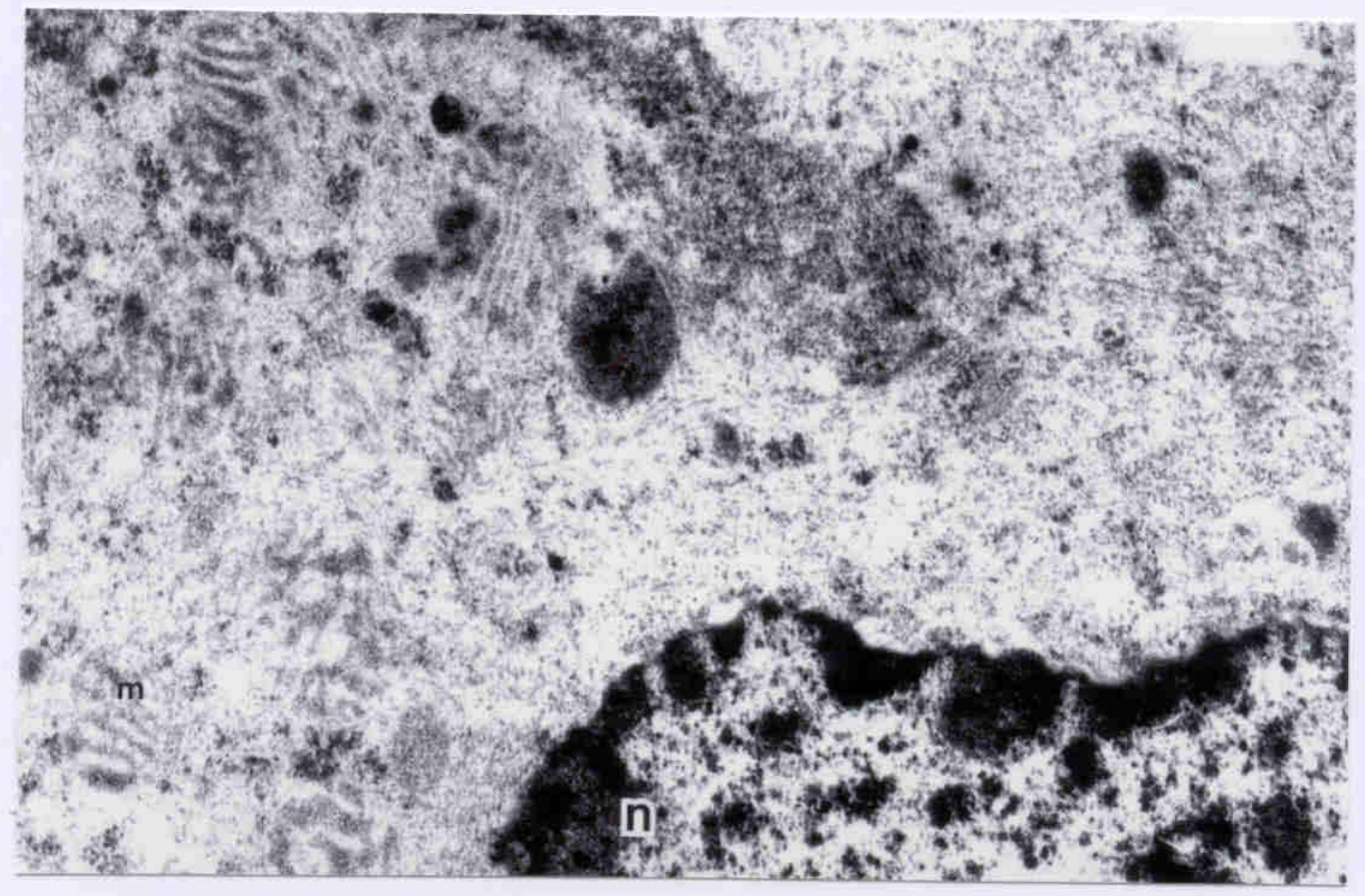

Fig. 2. Peak of luteolysis. Nearly all of the ER has disappeared and the mitochondria $(\mathrm{m})$ have become poorly defined. (X 20000). 